\title{
ATTITUDES OF NON-DISABLED STUDENTS TOWARDS THEIR PEERS WITH DISABILITIES IN AN INCLUSIVE SETTING IN GHANA
}

\author{
Francis Kwame Anku1, \\ Daniel S. Q. Dogbe', \\ Anthony Kofi Mensah ${ }^{2 i}$ \\ ${ }^{1}$ Mfantsipim School, \\ Cape Coast, Central Region, \\ Ghana \\ 2Department of Special Education, \\ University of Education, \\ Winneba, Central Region, \\ Ghana
}

\begin{abstract}
:
This study measured the attitudes of non-disabled students towards their peers with disabilities. A cross-sectional survey was employed for the study. The ChedokeMcMaster Attitudes Towards Children with "Handicaps" (CATCH) scale was used to collect data from $n=119$ respondents. Descriptive statistics analysis was employed in analysing the data. Results indicated that students without disabilities generally held neutral attitudes towards their peers with disabilities $(\mathrm{M}=2.12 ; \mathrm{SD}=0.687)$ with no significant difference in gender, age, having a close friend or relative with a disability. Teachers in inclusive education schools were encouraged to measure the attitudes of students towards their peers with disabilities and other related variables. This would enable them to plan, design, develop, implement and evaluate effective interventions that would change non-disabled students' negative and/or neutral attitudes, thereby ensuring the full social participation of students with disabilities in inclusive settings.
\end{abstract}

Keywords: attitudes, attitude measurement scale. inclusive education, inclusive setting

\section{Introduction}

Over the past decade, the inclusion of children with Special Educational Needs (SEN) in general education classrooms has become a global trend. In Ghana, a pilot inclusive education programme has expanded from 29 districts in seven regions in 2011 to 216 districts in 10 regions by 2016 (Arthur, Odoom, \& Boateng, 2016). It is anticipated that students with disabilities in general education schools - as opposed to attending special

' Correspondence: email ankufrancis20@gmail.com, ddogbe048@gmail.com, tonnymenz@gmail.com 
schools - have more possibilities for interaction and friendships with typically developing peers. After all, one of the core ideas behind inclusive education is that students with and without disabilities experience social benefits in attending general education schools together (Flem \& Keller, 2000; Hayford, 2013). However, research has repeatedly reported that inclusion alone does not automatically lead to more social contact and friendships between students with and without disabilities (Annan, 2014; Danso, 2009; Pijl, 2005; Rossetti, 2014; Schwab, Huber, \& Gebhardt, 2016). The attitudes of classmates or friends towards peers with disabilities can be regarded as an environmental factor that might facilitate or inhibit the social participation of students with Special Educational Needs (SEN) in inclusive education settings (Purutcuoglu \& Dogan, 2015; Vignes, Godeau, Sentenac, Coley, Navarro, Grandjean, \& Arnaud, 2009).

While positive peer relationships play a significant role in the development of students (both in learning and psychological outcomes), recent studies have established that students with SEN in inclusive classes often face problems with social participation (de Boer, Pijl \& Minnaert, 2012a, 2012b; Dias, Mamas, \& Gomes, 2020; Petry, 2018). In other words, negative peer attitudes have been commonly considered to be a major barrier to full social inclusion of students with disabilities in schools (Bebetsos, Zafeiriadis, Derri \& Kyrgiridis, 2013; Boakye-Akomeah, 2015; Dayan, 2017; Schwab, 2017). This may result in low acceptance by peers, few friendships, loneliness and even rejection and/or bullying (Aluede, Adeleke, Omoike, \& Afen-Akpaida, 2008; Lund, Nielsen, Hansen, Kriegbaum, Molbo, \& Due, 2009; Tavares, 2011). In light of this, further studies (Boakye-Akomeah, 2015; Danso, 2009; Gilson, Gushanas, Li \& Foster, 2020; Schwab, 2017) have linked these negative attitudes to exposure, or lack thereof. Owing to the possible consequences of negative attitudes, it is important to assess the attitudes of typically developing peers for appropriate interventions to predict, explain and manipulate reactions towards the attitude object.

A cursory observation of students at the Ghana National Basic School in Cape Coast revealed that students with disabilities were generally less involved by their peers without disabilities both in the classroom and in co-curricular activities such as sports and other recreational activities outside of school time. Basically, the said students with disabilities had fewer opportunities to interact with their typically developing peers. A study by Avramidis and Kalyva (2007) support the claim that students with disabilities in general education basic schools are less accepted and more rejected by their classmates without disabilities and have fewer stable friends than their peers.

Despite these findings, further investigation into variables relating to students' negative attitudes towards their peers with disabilities is relevant to serve as a foundation for teachers to develop interventions to change attitudes. Until now, research on the attitudes of students towards their peers with disabilities in Ghana is fairly scarce as compared to teachers' and parents' attitudes towards their inclusion. Teachers' lack of knowledge about the attitudes of non-disabled students towards their peers with disabilities might inhibit their ability to design intervention programmes to change students' attitudes. 
The findings of this study would reveal the attitudes of non-disabled students towards their peers with disabilities and its attendant variables. In this case, teachers, including other key stakeholders in inclusive education, would be informed about the factors that produce negative attitudes among students and the need for intervention to promote the social benefits of inclusive education. This research was, therefore, planned and conducted to examine non-disabled students' attitudes towards their peers with disabilities and the factors that influence them. This is an important step towards improving the social participation of students with SEN in inclusive schools.

\section{Purpose of the Study}

The purpose of this study was to examine the attitudes of non-disabled students towards their peers with disabilities at the Ghana National Basic School in Cape Coast. This was to determine the factors that influence the attitudes of students towards their peers with disabilities in inclusive settings. Two research questions were investigated: 1) What are the attitudes of non-disabled students towards their peers with disabilities at Ghana National Basic School? 2) What are the factors that influence the attitudes of students towards their peers with disabilities?

\subsection{Delimitation}

The scope of this study was delimited to only Junior High School (JHS) students without disabilities at the Ghana National Basic School in Cape Coast in the Central Region of Ghana. Hence, generalisation cannot be made about the attitudes of non-disabled students from other inclusive education schools.

\subsection{Limitation}

The attitude measurement scale used in this study had no specific description of the types of disabilities being referred to. Nevertheless, this did not have any significant effect on the results in that the respondents were familiar with their peers with disabilities and were also given adequate information about the categories of disabilities referred to in the study before data collection. The scale has the capacity to measure all the three components of attitudes and with an acceptable level of validity and test-retest reliability.

\section{Literature Review}

Within the field of social psychology, the concept of "attitude" is generally described in various ways. Despite this, no uniform definition can be made about this concept. For this current study, attitude is "an individual's viewpoint or disposition toward a particular 'object' (a person, a thing, an idea, etc.)" (Gall, Borg, \& Gall, 1996, p. 273). The authors also described it as "learned predispositions reflecting how favorable or unfavorable people are towards other people, objects or events" (Triandis, 1971, p. 266; cited by Kurtts \& Gavigan, 2017). Conceptually, attitudes are often described as a multidimensional concept, 
including (a) an affective component, involving statements of feelings towards children with disabilities, (b) behavioural component, involving statements about actual or intended behavior towards children with disabilities and (c) cognitive component, involving statements about beliefs and knowledge about children with disabilities (Kurtts \& Gavigan, 2017; Nowicki \& Sandieson, 2002). These three dimensions have been thought to be associated with one another and contribute to actual behaviours differently. Children with special educational needs often feel lonely in classrooms, are less accepted by their classmates, and have fewer friendships. Their classmates' positive attitudes towards them are important for their social participation in inclusive classrooms. Past research on students' attitudes has shown that children can be biased against peers with disabilities, but the association of attitudes with gender, age, and disability preferences, as well as interactions between these variables, are unclear. Nowicki (2006) examines the attitudes of elementary school children towards their peers with disabilities in a crosssectional, split-plot study to clarify: (1) if elementary school children's attitudes towards peers with disabilities are related to age, gender, and type of disability; (2) if interactions between these variables exist; and (3) if convergent validity could be achieved across three theoretically linked dependent variables. Results show that attitudes towards a target child with physical disabilities and a target child without disabilities did not differ. There was a significant interaction for age and disability. Attitudes towards target children with intellectual and intellectual/physical disabilities were negatively biased and were negatively associated with age.

Studies in Saudi Arabia and the United States have shown that some students without disabilities do not like the idea of inclusive education because they feel that students with special education needs would not be able to keep up with lessons taught in class (Dare, Nowicki \& Felimban, 2017; Downing \& Peckham-Hardin, 2007). Meanwhile, Bunch and Valeo's (2004) study in Canada observed that students without disabilities tend to advocate for their peers with disabilities in an inclusive setting and they sometimes develop friendships. Moreover, some students without disabilities demonstrate some positive behaviors toward peers with disabilities that indicate inclusion. Such behaviors include offering friendship and support, help with school work, and valuing friendship over academics (Lalvani, 2015). As a result of this, students with disabilities feel welcome and "important" when their counterparts without disabilities in the regular classroom engage them in a friendly relationship (Peck, Staub, Gallucci, \& Schwartz, 2004, as cited in Asamoah, Ofori-Dua, Cudjoe, Abdullah, Nyarko, 2018). Thus, attaining a balance between the needs of students with disabilities and those without disabilities could yield positive results for the success of inclusive education.

In a recent study, de Boer et al. (2012a, 2012b) presented an overview of studies describing attitudes of students, variables relating to students' attitudes, and the relationship between students' attitudes and the social participation of peers with disabilities. Based on a literature search, they selected 20 studies that were conducted in seven different countries. Outcomes were described in terms of negative, neutral, or positive according to three attitude components (cognitive, affective, and behavioural). 
The results show that students generally hold neutral attitudes towards peers with disabilities. Several variables were found relating to their attitudes (i.e., gender, age, experience with and knowledge about disabilities, parental influence).

Petry (2018) explored the relationship between the difficulties in social participation and attitudes that typically developing adolescents hold towards peers with disabilities at the level of the class Petry reported that students with autism spectrum disorder (ASD), as well as students with sensory and/or motor limitations, were less accepted by peers, had fewer reciprocal friendships, and were less engaged in peer interactions than their typically developing peers. The attitudes of typically developing adolescents towards their peers with disabilities at the level of the class were neutral. The relationship between class attitudes and peer acceptance, friendships, and peer interactions of students with ASD was moderated by type of disability.

Also, Dias, et al. (2020) used the Chedoke-McMaster Attitudes Towards Children (CATCH) with Special Needs Scale to examine the factors that influence the attitudes of students towards peers identified as having special educational needs (SEN) in mainstream schools. They indicate more favourable attitudes in girls, younger participants, and those with lower educational levels. Additionally, proximity, contact, and knowledge related to special educational needs appear to be determinants of positive attitudes. The discussion of inclusion in schools and gender appear to be the factors most associated with students' attitudes towards peers with special educational needs in mainstream education.

In contrast to earlier findings, Schwab (2015) found no differences for gender, nor between primary and secondary school students. This was a study conducted to draw upon an important distinction between the four main themes of social participation (friendships, interactions, peer acceptance, and self-perception of social participation) and examines these aspects in inclusive and regular classes, especially, differences in social participation of students with and without special educational needs (SEN) in inclusive classes and between students without SEN in inclusive and regular classes are examined. The results showed that in inclusive classes, students with SEN had lower scores on all four subthemes of social participation than students without SEN. Regarding students without SEN, friendships and peer acceptance were significantly higher in inclusive classes than in regular classes.

Hong, Eum, Long, Wu, and Welch (2020) investigated typically developing preschoolers' behavior towards peers with disabilities in inclusive classrooms, focusing on the co-occurrence of the interactions between children with and without disabilities with various classroom contexts. Behaviors of 22 typically developing preschoolers were observed and coded on two different days in both indoor and outdoor classrooms during free play, small group activities, transitions, and meals/snacks. Typically developing children interacted with peers with disabilities for a small amount of time; the interactions were significantly more likely in the outdoor classroom, in either child- or teacher-directed activities, and in play activities. There was a lack of adults' intentional scaffolding for social interactions between children with and without disabilities even 
when they were near the children. Activity contexts contribute to children's social behavior.

According to the theory of social referencing, children's attitudes towards peers with special educational needs are influenced by the role model behaviour of their parents. As a result, Hellmich and Loeper (2019) examined the relevance of children's perceptions of parental behaviour in terms of their attitudes towards peers with learning disabilities. This was done by investigating 753 children's attitudes, depending on their perceptions of parental behaviour towards peers with special educational needs, their contact experiences, and their self-efficacy beliefs concerning their interpersonal skills. The results indicated that their attitudes were predicted by their perceptions of parental behaviour, their contact experiences, and their self-efficacy beliefs. The effect of perceived parental behaviour on children's attitudes is mediated by their self-efficacy beliefs.

Most children and young people with disabilities living in developing countries face inequalities in education and other opportunities. In Ghana, studies measuring the attitudes of non-disabled students towards peers with disabilities in inclusive education schools appear scarce as compared to teachers and parents' attitudes (Agbenyega, 2007; Alhassan, 2014; Amissah, Gadosey, Nyarko, \& Agyemang, 2016; Amponteng, Opoku, Agyei-Okyere, Afriyie, \& Tawiah, 2019; Chitiyo, Kumedzro, Hughes, \& Ahmed, 2019; Subbey, 2020; Tamakloe, 2018). Asamoah, Ofori-Dua, Cudjoe, Abdullah, \& Nyarko (2018) investigate the perception of visually impaired students, their peers without disabilities, and teachers about inclusive education, focusing on a second-cycle educational institution in the Eastern region of Ghana implementing inclusive education for the visually impaired. They found out that visually impaired students and some teachers supported inclusion while a few students without disabilities disliked the practice.

Similar to a study in Nigeria, Olaleye, Ogundele, Deji, Ajayi, Olaleye and Adeyanju (2012) sought to describe the attitudes of students without disabilities towards their peers with disabilities in an inclusive school and assessed the role that gender and interpersonal contact play in shaping these attitudes. They carried out a cross-sectional study involving 107 students at an inclusive junior and senior secondary school. Participants were administered the $\mathrm{CATCH}$ measurement scale. Based on descriptive analysis, they reported positive attitudes of students in the school; however, female students were said to have been more positive than their male contemporaries. It was also found out that having a friend/relative with a disability was associated with more positive attitudes among female students.

In an earlier study by MacMillan, Tarrant, Abraham, and Morris (2014), systematically reviewed and synthesised observational evidence of associations between children's naturally varying contact with people with disabilities and their attitudes towards disabilities. After a comprehensive search was conducted across multiple databases, conclusions were drawn on studies that measure children's contact with people with disabilities and their attitudes towards disability. Studies identified in this review generally indicate that children's contact with people with disabilities is associated with more positive attitudes towards disability. There is a need for more 
rigorous research to examine the effect of children's contact with people with disabilities on their attitudes towards disability.

Schwab (2017) also utilised the inter-group contact theory in regular and inclusive classes to understand the relationship between contact with peers with Special Educational Needs (SEN) and students' attitudes towards their peers with SEN. Schwab used the CATCH scale to measure students' attitudes towards peers with learning disabilities and emotional disorders. Results indicate that students with SEN are less frequently nominated by their peers for joint activities, such as working together on a school project, while students from inclusive and regular classes did not differ in their attitudes towards peers with SEN. However, those students who nominated at least one peer with SEN for a joint activity had more positive attitudes towards peers with disabilities. Freely choosing to contact a peer with SEN was associated with more positive attitudes towards disability while simply attending the same class might have no effect or even a negative impact on students' attitudes.

Lindsay and Cancelliere (2018) identified four main themes that led to the progression of disability confidence among youth who volunteered with children who have a disability including (1) "disability discomfort," referring to lacking knowledge about disability and experiencing discomfort around people with disabilities; (2) "reaching beyond comfort zone" where participants increased their understanding of disability and became sensitized to difference; (3) "broadened perspectives" where youth gained exposure to people with disabilities and challenged common misperceptions and stereotypes; and (4) "disability confidence" which includes having knowledge of people with disabilities, inclusive, and positive attitudes towards them.

Certain variables in this literature review were found to be related to students' attitudes towards peers with disabilities: gender, type of disability, and age. Females were generally found to be more positive towards peers with disabilities (de Boer, 2012a, 2012b; Olaleye, et al., 2012; Vignes et al., 2009). Schwab (2015) and Hong et al. (2020) found no difference for gender. Children with a relative or friend with a disability were found to be more open towards peers with disabilities (Olaleye et al., 2012; Vignes et al., 2009). Furthermore, results on the effect of age were inconsistent. Some authors found no age-effect (Schwab, 2015; Vignes et al., 2009), other authors claimed that children's attitudes towards peers with disabilities showed more tolerance as they aged (Dias et al., 2020; Brook \& Galili, 2000). Results on the effects of 'disability knowledge' factors among students are inconsistent. Some authors found that adolescents with more prior knowledge about persons with disabilities have more positive attitudes towards them (Brook \& Galili, 2000; Garrote \& Rachel, 2015; Lindsay \& Cancelliere, 2018; Vignes et al., 2009), whereas others did not find a correlation between prior knowledge and attitudes (MacMillan et al., 2014; Schwab, 2017). Furthermore, several studies show a positive effect of direct contact with peers with disabilities on children's attitudes (Schwab, 2017), whereas other researchers have added that the type of relation between the individuals does not affect students' attitudes (Olaleye et al., 2012; Vignes et al., 2009). In the latter studies, only adolescents with more frequent contact with persons with disabilities and 
adolescents who had friends with disabilities held more positive perspectives on meeting people with disabilities.

Additionally, several studies among basic school students have revealed differences in social participation of students with different types of disabilities. For example, students with ASD, severe behavior, and communication problems experience more social difficulties compared to students with other types of disabilities (Humphrey \& Symes, 2013; Pijl, Frostad \& Flem, 2008). Moreover, the social participation levels of students with sensory and motor disabilities were most comparable to the ones of typically developing peers (Pijl et al., 2008). However, these studies have been remotely current. To the knowledge of this review, no significant research has been conducted on students' attitudes towards peers with different types of disabilities in Ghanaian inclusive basic schools. Based on these findings, more research must be conducted to ascertain the variables relating to students' attitudes towards their peers with disabilities in inclusive schools in order to design, develop and implement appropriate interventions for attitudes change.

\section{Method}

The quantitative approach was used in response to research questions. The procedures were informed by postpositivism worldview to provide room for the measurement of attitudes. A cross-sectional survey of non-disabled students' attitudes towards their peers with disabilities was used. The study was conducted in Ghana National Basic School in Cape Coast in the Central Region of Ghana. One hundred and nineteen respondents were selected from a group of 144 Junior High School (JHS) students without disabilities from form one to three who share the same classrooms as their peers with disabilities, and are familiar with them. In this school. After permission was sought, the quota sampling technique was used to sample the 119 students without disabilities for the study.

\subsection{Instrumentation}

The second part of the questionnaire included items assessing attitudes towards people with disabilities. The Chedoke-McMaster Attitudes Towards Children with "Handicaps" (CATCH) was used to measure the attitudes. The CATCH scale has been recommended as a reliable, valid, and comprehensive measure of children's attitudes towards peers with disabilities in a review of instruments (Beck, Fritz, Keller, \& Dennis, 2000; Olaleye1 et al., 2012; Rosenbaum, Armstrong \& King, 1986; Vignes, Coley, Grandjean, Godeau, \& Arnaud, 2008). It was developed by Rosenbaum, Armstrong, and King (1988) as one of the most complete instruments since it measures all the three components of attitudes: affective, behavioural, and cognition (Feldman, 1993; Tirosh, 1997). The CATCH scale is a self-administered questionnaire that elicits responses on a Likert scale numbered 0 to 4 (0-strongly disagree, 1-disagree, 2-neutral, 3-agree, 4-strongly agree) and comprises 36 items. Each subscale (affective, behavioural intention, and cognitive) has 12 items. The instrument was pre-tested at Oduponkpehe Inclusive Basic School at Kasoa in the Central 
Region and it yielded Cronbach Alpha of 0.832 for the full CATCH scale. The internal consistency for the subscales (affective attitudes, behavioural intentions, and cognitive attitudes) included $0.639,0.737$, and 0711, respectively. Data collection spanned a week. The questionnaires were distributed to the students with the assistance of the class teachers, and it took 25 to 30 minutes to fill in.

\subsection{Data Analysis}

Data was entered into Statistical Product and Service Solutions (SPSS) version 21.0. Responses to items on the $\mathrm{CATCH}$ scale were classified into three categories: agree, neutral, and disagree. Strongly agree, as well as strongly disagree, were included in the agree and disagree categories, respectively. In addition, statements with positive meanings $(n=18)$ were processed using the scale: Agree $(A)=1$; Neutral $(N)=2$; and Disagree $(D)=3$; whereas statements with negative meanings $(n=18)$ were processed in a reversed manner; that is $\mathrm{D}=1, \mathrm{~N}=2$, and $\mathrm{A}=1$. Attitude scores for each domain and the total CATCH score were analysed separately. In the case of missing items, the mean of the other items within the same domain was used if no more than one item was missing for that domain; otherwise, these data were excluded. The attitudes of students towards their peers with disabilities were indicated using descriptive statistics. On the CATCH scale, a value of 1 (Agree) indicated positive; 3 (Disagree) suggested a negative attitude compared to 2 (Neutral) which suggested neither a positive nor negative attitude. In addition, all the 36 items on the $\mathrm{CATCH}$ scale were analysed to obtain the total CATCH score for each domain of attitude as in previous studies (Olaleye et al., 2012; Rosenbaum et al., 1986; Tirosh et al., 1997). The dependent variables were the proportions of the responses to items on the scale, the scores on cognition, affective, and behaviour, as well as the total CATCH scores. Data analysis was carried out in Statistical Product and Service Solutions (SPSS) - version 21.0 to minimise bias. The significance of differences in the CATCH scores between groups of participants was analysed using paired sample $t$-test at a level of significance of $p<0.05$. The $t$-test analysis was, therefore, carried out between the pretest and the posttest results to indicate the effect size on the treatment group.

\section{Results and Discussion}

Table 1: Demographic characteristics

\begin{tabular}{|l|c|c|}
\hline Demographic variables & $\begin{array}{c}\text { Frequency } \\
\text { (n=119) }\end{array}$ & $\begin{array}{c}\text { Percentage } \\
\text { (\%) }\end{array}$ \\
\hline Gender & 55 & 46.2 \\
\hline Males & 64 & 53.8 \\
\hline Females & 3 & 2.5 \\
\hline Age (in years) & 103 & 86.6 \\
\hline Under 12 years & 12 & 10.1 \\
\hline 12-14 years & 1 & 0.8 \\
\hline 15-16 years & \multicolumn{3}{|l|}{} \\
\hline Above 16 years &
\end{tabular}




\begin{tabular}{|c|c|c|}
\hline \multicolumn{3}{|l|}{ Class } \\
\hline JHS 1 & 39 & 32.8 \\
\hline JHS 2 & 58 & 48.7 \\
\hline JHS 3 & 22 & 18.5 \\
\hline \multicolumn{3}{|c|}{ Had a relative with a disability } \\
\hline Yes & 11 & 9 \\
\hline No & 100 & 84 \\
\hline *Missing data & 8 & 7 \\
\hline \multicolumn{3}{|c|}{ Had a close friend with a disability } \\
\hline Yes & 13 & 11 \\
\hline No & 85 & 71 \\
\hline${ }^{*}$ Missing data & 21 & 18 \\
\hline \multicolumn{3}{|c|}{ Had read children's literature prior to the study } \\
\hline Yes & 119 & 100 \\
\hline No & 0 & 0 \\
\hline
\end{tabular}

*Missing data implies respondents who did not respond either 'Yes' or ' $\mathrm{No}^{\prime}$.

Note: Field data, 2020.

\subsection{Gender}

Table 1 presents the analysis of the results of the demographic characteristics of the respondents. The table shows that out of the 119 respondents, 55(46.2\%) were males, and $64(53.8 \%)$ were females. Gender disparity has been highly skewed in favour of females. This is because the school had females as the majority. Perhaps the preponderance of female participants in the schools was because of more advocacy for girl-child education in recent years which aligns with the philosophy of inclusive education.

\subsection{Age}

Apart from three (2.5\%) respondents who were under 12 years. Table 1 indicates that the majority of the respondents $103(86.6 \%)$ were aged between 12 years old and14 years old, whereas $12(10.1 \%)$ were aged between 15 years old and 16 years old. Besides, only one respondent, representing $0.8 \%$, was above 16 years of age. This shows that majority of the respondents were within what is normally described as the ideal age range for junior high school in Ghana.

\subsection{Class}

The grade level of the respondents was also of interest to the researcher. From Table 1, participants in Junior High School One (JHS 1) were 39(32.8\%), those in JHS 2 were $58(48.7 \%)$, and $22(18.5 \%)$ were in JHS 3. Participants in JHS 2, therefore, formed the majority, followed by JHS 1 students. The least number of participants in the study were in JHS 3.

\subsection{Have a Relative with a Disability}

Three (2.5\%) participants, as shown in Table 1, responded in the affirmative that they have relatives with disabilities, whilst $116(97.5 \%)$ reported otherwise. This is an indication that the majority of the respondents have little or no experience with persons 
with disabilities at home. The school is probably their first place of contact with individuals with disabilities.

\subsection{Have a Close Friend with a Disability}

On the issue of whether respondents have close friends with disabilities, only six (5.1\%) assented as against 112(94.9\%) who stated that they did not have close ties with persons with disabilities. It is obvious that students with disabilities do not get opportunities to interact with their peers without disabilities even though they are all in the same school environment. In other words, a mere placement of students with and without disabilities did not lead to social contact and friendships between them.

\subsection{Students' Attitudes Towards their Peers with Disabilities in Inclusive Education Settings}

Table 3 to Table 5 show the pretest data on the three attitude components that were presented in frequencies and percentages, including their mean and standard deviation scores. The mean scores, within subscales, which were statistically significant, were also described and interpreted in the said tables.

Table 4: Participants' responses on the affective component of the CATCH scale

\begin{tabular}{|l|c|c|c|c|}
\hline Item & $\begin{array}{c}\mathbf{A} \\
\mathbf{f}(\%)\end{array}$ & $\begin{array}{c}\mathbf{N} \\
\mathbf{f ( \% )}\end{array}$ & $\begin{array}{c}\mathbf{D} \\
\mathbf{f}(\%)\end{array}$ & $\mathbf{M}(\mathrm{SD})$ \\
\hline $\begin{array}{l}\text { 1. I would not mind if a child with a disability sits next to } \\
\text { me. }\end{array}$ & $30(25.2)$ & $52(43.7)$ & $37(31.1)$ & $2.06(.751)$ \\
\hline $\begin{array}{l}\text { 2. I would not introduce a child with a disability to my } \\
\text { friend. }\end{array}$ & $20(16.8)$ & $60(50.4)$ & $39(32.8)$ & $2.16(.689)$ \\
\hline $\begin{array}{l}\text { 3. } \text { Children with disabilities can do lots of things for } \\
\text { themselves. }\end{array}$ & $22(18.6)$ & $46(39.0)$ & $50(42.4)$ & $2.24(.747)$ \\
\hline $\begin{array}{l}\text { 4. I would not know what to say to a child with a } \\
\text { disability. }\end{array}$ & $21(17.6)$ & $55(46.2)$ & $43(36.1)$ & $2.18(.713)$ \\
\hline 5. Children with disabilities like to play. & $31(26.1)$ & $50(42.0)$ & $38(31.9)$ & $2.06(.762)$ \\
\hline 6. I feel sorry for children with disabilities. & $26(21.8)$ & $58(48.7)$ & $35(29.4)$ & $2.08(.715)$ \\
\hline $\begin{array}{l}\text { 7. I would defend a child with a disability who was being } \\
\text { teased. }\end{array}$ & $50(42.0)$ & $58(48.7)$ & $11(9.2)$ & $1.67(.639)$ \\
\hline $\begin{array}{l}\text { 8. Children with disabilities want lots of attention from } \\
\text { adults. }\end{array}$ & $13(10.9)$ & $63(52.9)$ & $43(36.1)$ & $2.25(.641)$ \\
\hline $\begin{array}{l}\text { 9. I would invite a child with a disability to my birthday } \\
\text { party. }\end{array}$ & $16(13.4)$ & $64(53.8)$ & $39(32.8)$ & $2.19(.655)$ \\
\hline 10. I would be afraid of a child with a disability. & $17(14.3)$ & $63(52.9)$ & $39(32.8)$ & $2.18(.663)$ \\
\hline $\begin{array}{l}\text { 11. I will talk with a child with a disability I did not } \\
\text { know. }\end{array}$ & $23(19.3)$ & $66(55.5)$ & $30(25.2)$ & $2.06(.668)$ \\
\hline 12. Children with disabilities do not like to make friends. & $23(19.3)$ & $60(50.4)$ & $36(30.3)$ & $2.11(.699)$ \\
\hline 13. Average mean and standard deviation & $24(20.4)$ & $58(48.7)$ & $37(30.8)$ & $2.10(.695)$ \\
\hline
\end{tabular}

*Missing data.

Note: Field data, 2020. $\mathrm{M}=$ Mean, SD = Standard Deviation. 
From Table 2, items one to 12 sought to describe the affective component of students' attitudes in the study. In expressing their values and emotions towards their peers with disabilities, 24 respondents on average, representing $20.4 \%$, were negative in towards their peers with disabilities. While 58(48.7\%) were neutral, the rest 37 respondents, representing $30.8 \%$ were positive towards their peers with disabilities.

Furthermore, from Table 2, the corresponding mean, standard deviation, median and interquartile range have been presented. Based on the scores generated, it was revealed that students without disabilities in Ghana National Basic School showed neutral attitudes towards their peers with disabilities $(\mathrm{M}=2.10 ; \mathrm{SD}=0.695)$. This domain (affective) generated the lowest mean and standard deviation scores among the three models of attitude content. The minimum and maximum mean scores ranged between $\mathrm{M}=1.67$ and $\mathrm{M}=2.25$, and that of standard deviation was $\mathrm{SD}=0.639$ and $\mathrm{SD}=0.762$, respectively. Results reveal that students with disabilities can sit next to their counterparts without disabilities in the same classroom environment. Since both students with and without disabilities already study together in the same classroom it was expected that the latter should be quite familiar and comfortable with their counterparts with disabilities. It is, thus, not surprising that students' values and emotions are not negative, but neutral. Table 3 shows participants' responses on the behavioural component of the CATCH scale.

Table 3: Participants' responses on the behavioural component of the CATCH scale

\begin{tabular}{|l|c|c|c|c|}
\hline Item & $\begin{array}{c}\mathbf{A} \\
\mathbf{f}(\%)\end{array}$ & $\begin{array}{c}\mathbf{N} \\
\mathbf{f ( \% )}\end{array}$ & $\begin{array}{c}\mathbf{D} \\
\mathbf{f ( \% )}\end{array}$ & $\mathbf{M ( S D )}$ \\
\hline $\begin{array}{l}\text { 1. I would like a child with a disability to live next } \\
\text { door to me. }\end{array}$ & $20(16.8)$ & $62(52.1)$ & $37(31.1)$ & $2.14(.680)$ \\
\hline 2. ${ }^{*}$ Children with disabilities feel sorry for themselves. & $18(15.3)$ & $62(52.5)$ & $38(32.2)$ & $2.17(.671)$ \\
\hline $\begin{array}{l}\text { 3. I would be happy to have a child with a disability } \\
\text { as a best friend. }\end{array}$ & $22(18.5)$ & $58(48.7)$ & $39(32.8)$ & $2.14(.705)$ \\
\hline $\begin{array}{l}\text { 4. }{ }^{*} \text { I would try to stay away from a child with a } \\
\text { disability. }\end{array}$ & $22(18.8)$ & $48(41.0)$ & $47(40.2)$ & $2.21(.741)$ \\
\hline 5. Children with disabilities are as happy as I am. & $27(22.7)$ & $56(47.1)$ & $36(30.3)$ & $2.08(.727)$ \\
\hline $\begin{array}{l}\text { 6. I would not like a friend with a disability as much } \\
\text { as my other friends. }\end{array}$ & $20(16.8)$ & $71(59.7)$ & $28(23.5)$ & $2.07(.634)$ \\
\hline $\begin{array}{l}\text { 7. }{ }^{*} \text { Children with disabilities know how to behave } \\
\text { properly. }\end{array}$ & $20(16.9)$ & $52(44.1)$ & $46(39.0)$ & $2.22(.718)$ \\
\hline $\begin{array}{l}\text { 8. In class, I would not sit next to a child with a } \\
\text { disability. }\end{array}$ & $20(16.8)$ & $58(48.7)$ & $41(34.5)$ & $2.18(.697)$ \\
\hline $\begin{array}{l}\text { 9. I would be pleased if a child with a disability } \\
\text { invited me to his house. }\end{array}$ & $13(10.9)$ & $66(55.5)$ & $40(33.6)$ & $2.23(.630)$ \\
\hline 10. ${ }^{*}$ I try not to look at someone who has a disability. & $18(15.1)$ & $52(44.1)$ & $48(40.7)$ & $2.25(.706)$ \\
\hline $\begin{array}{l}\text { 11. I would feel good doing a school project with a } \\
\text { child with a disability. }\end{array}$ & $23(19.3)$ & $59(49.6)$ & $37(31.1)$ & $2.12(.703)$ \\
\hline 12. Children with disabilities do not have much fun. & $22(18.5)$ & $61(51.3)$ & $36(30.3)$ & $2.12(.691)$ \\
\hline Average mean and standard deviation scores & $20(17.1)$ & $59(49.5)$ & $39(33.3)$ & $2.16(.691)$ \\
\hline
\end{tabular}

${ }^{*}$ Missing data.

Note: Field data, 2020 
On the behavioural component of attitudes, which targeted information on the mental representation of students' current, past, and future behaviours regarding their peers with disabilities, items 13 to 24 on Table 3 were considered averagely. Out of 119 respondents, 20, representing $17.1 \%$ agreed to the statements to suggest negative attitudes towards their peers with disabilities. Fifty-nine $(49.5 \%)$ were neutral while $39(33.3 \%)$ were favourable in their attitudes towards their peers with disabilities.

The statistical scores for the mean and standard deviation indicate students' neutral attitudes towards their peers with disabilities. These scores are higher relative to the average scores for the affective component in Table $1(\mathrm{M}=2.16$; $\mathrm{SD}=.691)$. For the behavioural component of attitudes, a minimum and maximum mean score were $\mathrm{M}=$ 2.07 and $\mathrm{M}=2.25$, whereas that of the standard deviation generated $\mathrm{SD}=0.630$ and $\mathrm{SD}=$ 0.741 . This implies that the behavioural characteristics of students towards their peers with disabilities were almost negative. Table 4 shows participants' responses on the cognitive component of the CATCH scale.

Table 4: Participants' responses on the cognitive component of the CATCH scale

\begin{tabular}{|l|c|c|c|c|}
\hline Item & $\begin{array}{c}\mathbf{A} \\
\mathbf{f ( \% )}\end{array}$ & $\begin{array}{c}\mathbf{N} \\
\mathbf{f ( \% )}\end{array}$ & $\begin{array}{c}\mathbf{D} \\
\mathbf{f ( \% )}\end{array}$ & $\mathbf{M ( S D )}$ \\
\hline $\begin{array}{l}\text { 1. }{ }^{*} \text { I would invite a child with a disability to sleep } \\
\text { over at my house. }\end{array}$ & $22(18.6)$ & $65(54.6)$ & $31(26.3)$ & $2.08(.669)$ \\
\hline 2. Being near someone who has a disability scares me. & $19(16.0)$ & $66(55.5)$ & $34(28.6)$ & $2.13(.658)$ \\
\hline $\begin{array}{l}\text { 3. Children with disabilities are interested in lots of } \\
\text { things. }\end{array}$ & $25(21.0)$ & $64(53.8)$ & $30(25.2)$ & $2.04(.681)$ \\
\hline $\begin{array}{l}\text { 4. I would be embarrassed if a child with a disability } \\
\text { invited me to his birthday party. }\end{array}$ & $19(16.1)$ & $57(47.3)$ & $42(35.6)$ & $2.19(.695)$ \\
\hline 5. ${ }^{*}$ I would tell my secret to a child with a disability. & $19(16.1)$ & $72(61.0)$ & $27(22.9)$ & $2.07(.623)$ \\
\hline 6. Children with disabilities are often sad. & $25(21.0)$ & $58(48.7)$ & $36(30.3)$ & $2.09(.713)$ \\
\hline 7. I would enjoy being with a child with a disability. & $22(18.5)$ & $62(52.1)$ & $35(29.4)$ & $2.11(.686)$ \\
\hline $\begin{array}{l}\text { 8. }{ }^{*} \text { I would not go to a child with a disability's house } \\
\text { to play. }\end{array}$ & $25(21.2)$ & $57(48.3)$ & $36(30.5)$ & $2.09(.716)$ \\
\hline 9. Children with disabilities can make new friends. & $17(14.3)$ & $68(57.1)$ & $34(28.6)$ & $2.14(.642)$ \\
\hline 10. I feel upset when I see a child with a disability. & $25(21.0)$ & $57(47.9)$ & $37(31.1)$ & $2.10(.718)$ \\
\hline $\begin{array}{l}\text { 11. I would miss break time to keep a child with a } \\
\text { disability company. }\end{array}$ & $27(22.7)$ & $65(54.6)$ & $27(22.7)$ & $2.00(.676)$ \\
\hline $\begin{array}{l}\text { 12. }{ }^{*} \text { Children with disabilities need lots of help to do } \\
\text { things. }\end{array}$ & $17(14.4)$ & $69(58.0)$ & $32(27.1)$ & $2.13(.634)$ \\
\hline Average mean and standard deviation scores & $22(18.4)$ & $63(53.2)$ & $33(28.2)$ & $2.10(.676)$ \\
\hline
\end{tabular}

*Missing data.

Note: Field data, 2020.

The last group of 12 items in Table 4 covers the cognitive component of attitudes. This was focused on students' beliefs, thoughts, and attributes associated with their peers with disabilities. Twenty-two (18.4\%) respondents agreed to all the items, indicating negative attitudes towards their peers with disabilities. Even though the majority 63(53.2\%) showed neutral attitudes, 33(28.2\%) were positive in their attitudes. 
Table 4 also shows the statistical scores generated for the mean and the standard deviation. The average corresponding mean and standard deviations were $M=2.10$ and $\mathrm{SD}=0.676$, respectively. A minimum mean and standard deviation scores were $\mathrm{M}=2.00$ and $\mathrm{SD}=0.623$ and a maximum mean and standard deviation included $\mathrm{M}=2.19$ and $\mathrm{M}$ $=0.718$. Compared to the affective and behavioral components of attitudes, the cognitive domain recorded the highest statistical scores. This means that students' attitudes across all the components are not positive, but neutral. They, therefore, needed an intervention to encourage positive attitudes among them as a way of fostering the social participation of inclusive education. The data presented in the tables helped to answer research question one. Table 5 displays the differences in the mean and the standard deviation scores for both male and female respondents.

Table 5: Mean and standard deviation scores for both male and female respondents

\begin{tabular}{|l|c|c|c|c|c|c|c|c|}
\hline \multirow{2}{*}{ Variable } & \multicolumn{2}{|c|}{ Min } & \multicolumn{2}{c|}{ Max } & \multicolumn{2}{c|}{ Average } & \multicolumn{2}{c|}{ Sum } \\
\cline { 2 - 9 } & M & SD & M & SD & M & SD & M & SD \\
\hline Sex & & & & & & & & \\
\hline Male & 1.58 & 0.554 & 2.35 & 0.764 & 2.14 & 0.684 & 77.12 & 24.630 \\
\hline Female & 1.75 & 0.572 & 2.33 & 0.776 & 2.10 & 0.687 & 75.73 & 24.714 \\
\hline Total & 3.36 & 1.126 & 4.68 & 1.54 & 4.24 & 1.371 & 152.85 & 49.344 \\
\hline
\end{tabular}

Results relating to the gender of the respondents are presented in Table 5. Of the total number of respondents who took the pretest $(n=119)$, the male respondents generated a minimum mean score of $\mathrm{M}=1.58$ with $\mathrm{SD}=0.554$ standard deviation and a maximum mean score of $\mathrm{M}=2.35$ with $\mathrm{SD}=0.764$ standard deviations. The male average score for the mean was 2.14 and 0.684 standard deviation, as well as a mean sum of $\mathrm{M}=77.12$ and standard deviation sum of $\mathrm{SD}=24$.630. In comparison, the general attitude of female respondents statistically reported a minimum mean score of $\mathrm{M}=1.75$ with $\mathrm{SD}=0.572$ standard deviation and $\mathrm{M}=2.29$ maximum mean score and a standard deviation of $\mathrm{SD}=$ 0.776. the average mean score regarding females was $\mathrm{M}=2.10$ with a standard deviation of $\mathrm{SD}=0.689$. the sum of the full CATCH scale observed a mean of $\mathrm{M}=73.4$ and a standard deviation of $\mathrm{SD}=24.122$ standard deviation. Overall, the attitudes of respondents towards their peers with disabilities were statistically neutral with the females recording more neutral attitudes slightly over their male counterparts. The total average scores for each domain of attitudes of the respondents on the CATCH scale are represented in Figure 1.

Figure 1 indicates the average mean scores for the three components of attitudes (affective, behavioural, and cognitive) range from $M=25.17$ to $M=25.93$. The cognitive domain of attitudes had the lowest average mean score of $\mathrm{M}=25.17$ and standard deviation of $\mathrm{SD}=8.111$. All the three components of attitudes generated the same mean average score of $\mathrm{M}=24$. Overall, the results indicate fairly neutral attitudes, and this warranted an intervention to measure the change in attitudes or otherwise among students towards their peers with disabilities. 
Figure 1: Total mean and standard deviation scores of respondents on the CATCH scale

\section{$\mathrm{CATCH}$ subscale average scores}

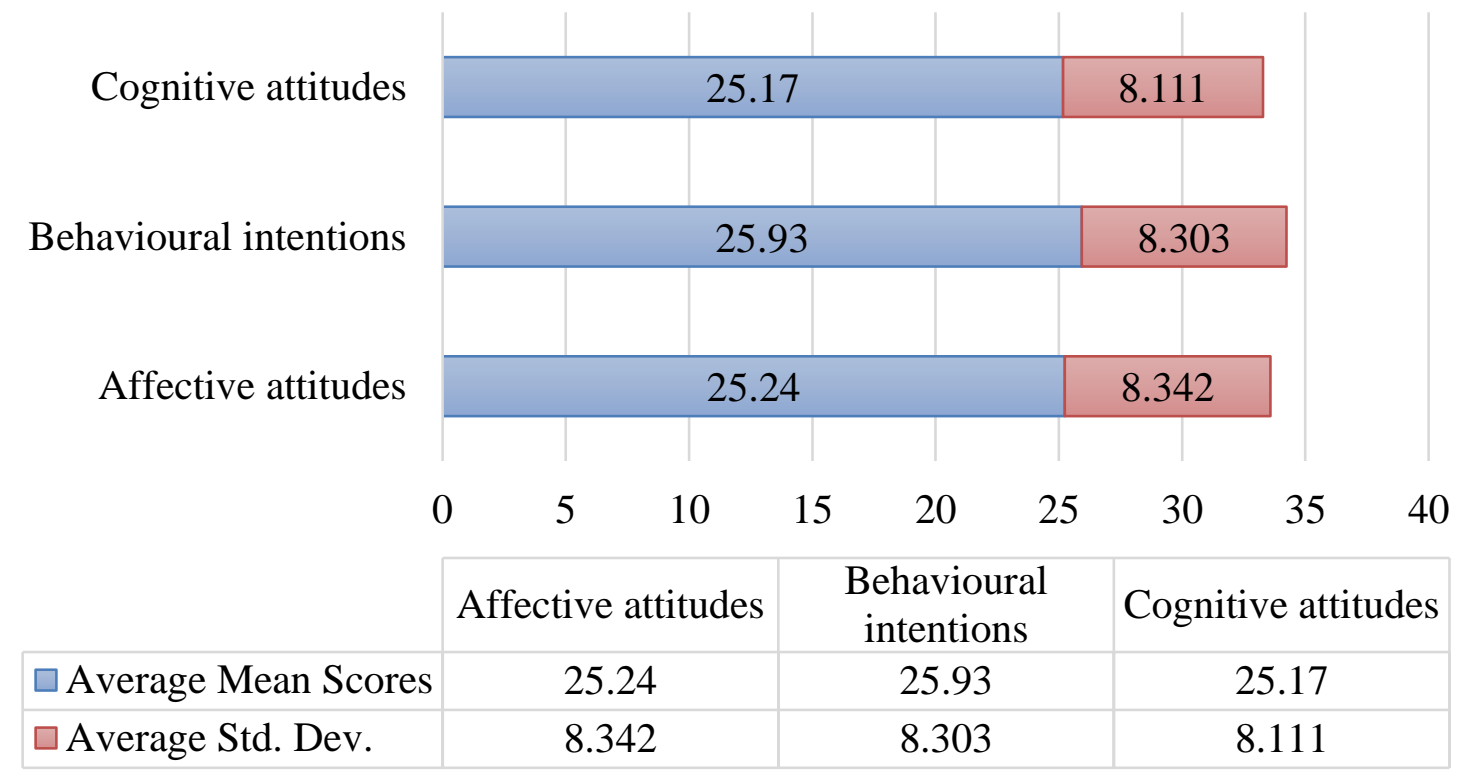

$\square$ Average Mean Scores $\quad \square$ Average Std. Dev.

\section{Discussion}

The use of $\mathrm{CATCH}$ at the pretest stage afforded the researcher the opportunity to assess the attitudes of students towards their peers with disabilities prior to their exposure to children's literature. In general, respondents in this study expressed natural attitudes towards their peers with disabilities, a result that concurs with other studies (Vignes et al., 2009; Nowicki \& Sandieson, 2002; Petry, 2018). According to related surveys (de Boer et al., 2012a, 2012b; Petry, 2018), students presented higher attitudes scores, but they still fall within a neutral attitude. That is, results in this study show that students generally hold neutral attitudes towards peers with disabilities $(\mathrm{M}=2.12$; $\mathrm{SD}=0.687)$. However, results on the effect of gender on the attitudes of students with disabilities have been inconsistent. In this study, no statistically significant difference was observed for gender in relation to the attitudes of students towards their peers with disabilities, a finding that is in accordance with other studies (Schwab, 2015; Hong et al., 2020) although Dias et al. (2020) and Olaleye et al. (2012) found girls to express more favourable attitudes than boys. One could argue that the neutral outcomes of this study are no reason for concern as, at least, they are not negative. However, it is important to consider that the averages indicating neutral scores are based on data with sometimes considerable variance. Despite the overall neutral score, there were also students holding far more positive or far more negative attitudes. Even a small group of students holding negative attitudes can make life at school for a child with a disability very difficult (McDougall et al., 2004, 
as cited by de Boer et al., 2012). Hence, this indicates that such neutral scores also imply several students with negative attitudes.

Concerning the three components of attitudes - affective, behavioural, and cognitive - the behavioural dimension recorded a significantly highest average mean of $\mathrm{M}=2.16$ with a standard deviation of $\mathrm{SD}=.691$ more than the affective and cognitive components which had a common mean of $\mathrm{M}=2.10$ but different standard deviations: SD $=695$ and SD = 676, respectively. This, according to Kurtts and Gavigan (2017) implies that the feelings, beliefs, and knowledge of students towards their peers with disabilities are more satisfactory than their actual or intended behaviour. These three dimensions have been thought to be associated with one another and contribute to actual behaviours differently. The affective aspect of attitudes may be associated with behavioural intentions or actual behaviours; the cognitive aspect of attitudes may also be linked to the behavioural aspect of attitudes and the cognitive aspect of attitudes may be associated with the affective aspect of attitudes (Wood \& Orpinas, 2020; Garrote et al., 2020; Freer, 2018; Hong et al., 2014; de Boer \& Pijl, 2016). For instance, when information is processed and incorrectly structured in the cognitive system (cognitive dimension of conception), inadequate attitudes may then be formed (affective dimension of conception). Misconception may therefore be projected as negative prejudices, stereotypes, and invalid generalisations with attitudes and modes of behaviour of a pupil and directed at the concept, phenomenon, problem, or a person - as an attitude towards somebody with a disability.

Results from focus group discussion on the outcome of the pretest reveal that students' negative perceptions and their insufficient knowledge of disability influenced their earlier responses. Students' false notions about disability and incorrect interpretations stemmed from incomplete information, limited experience, or invalid generalization. This might be the reason why many students were neutral in their attitudes towards their peers with disabilities as they did not want to sound negative. As noted by Mjaavatn et al. (2015), young children have a basic level of understanding of disabilities and can distinguish at least some types of disabilities and learn positive attitudes. Rose et al. (2015) and Petry (2018) supported the assertion that a basic level of understanding of disabilities may be related to their feelings about peers with disabilities since having a better understanding of another group of people may promote positive feelings about them and reduce fears about people with disabilities that might result partly from the lack of knowledge. Likewise, many other studies also support the argument that students with more prior knowledge about persons with disabilities have more positive attitudes towards them (Garrote \& Rachel, 2015; Lindsay \& Cancelliere, 2018).

Furthermore, it was discovered that students with disabilities have fewer friends (defined as 'reciprocal ties' between students) than those without disabilities. In other words, most of the students with disabilities, according to interactions with interviewees, do not take part in many co-curriculum activities while in school. They are not involved because their counterparts without disabilities (interviewees) probably felt that these 
activities had so many rules that compromised their participation. It is also quite clear that students' ability to befriend peers with disabilities was based on personality and lack of understanding of what disability is. This implies that making friends revolves around the personal attributes of an individual. Some interviewees did not want children with disabilities as friends because they thought children with disabilities are dull, anti-social, sad, scary, cannot make new friends, and so on; while others also believed that they would not benefit from the friendship. There is also some suggestion that they have fewer reciprocal friendships, lower-quality friendships, less stable friendships, are victimized by peers, and are more likely to succumb to peer pressure (Estell et al., 2009).

Another related theme that informed the neutral attitudes of participants towards their peers with disabilities was low acceptance. Results indicated that children who are perceived by their peers as bright or displaying quiet/good behaviour are more likely to be accepted. In contrast, children who are perceived by their peers as dull or displaying disruptive behaviour are more likely to be rejected. This shows an association between acceptance and positive behavioural characteristics as perceived by peers, and between rejection and negative behavioural characteristics as perceived by peers. Students therefore deliberately exclude their peers from social relationships or interactions by ignoring them or giving them the silent treatment. Williams and Inkster (2005), and McDougall et al. (2001) advanced that low acceptance may lead to many different psychological consequences such as loneliness, low self-esteem, aggression, and depression. It can lead to feelings of insecurity and heightened sensitivity to future rejection. Through focus group discussion, it was realized that students maintain rather negative or neutral attitudes towards their peers with intellectual disabilities compared to another type of disability: sensory impairment. This assertion is maintained by Hayes and Bulat (2017) that one of the groups most at risk of social exclusion, marginalization, and segregation are people with an intellectual disability. These findings corroborate with Allport's theory (1954) that although direct contact between different groups may be essential for positive interactions, not all types of contact between diverse groups lead to acceptance of each other. Therefore, a common belief that merely assembling diverse groups of people together facilitates acceptance of each other is largely refuted.

There is, thus, an indication that students with disabilities in this study have fewer reciprocal friendships, lower-quality friendships, less stable friendships, victimised by peers, and are more likely to succumb to peer pressure. In all, the existing attitudes of interviewees were based on the negative perceptions about their peers with disabilities, low acceptance, and few friendships of peers with disabilities. However, one of the conditions set by Allport (1954 as revised by Pettigrew, 2011) is that students should be given the opportunity to get to know the peer with a disability as an individual (opportunity to interact) rather than as a stereotype or label (stereotype disconfirmation) could help foster the acceptance of a peer with a disability. 


\section{Recommendation}

Teachers in inclusive education schools should measure the attitudes of students towards their peers with disabilities and other related variables in order that they would be able to plan, design, develop, implement and evaluate effective interventions that would change negative attitudes. Also, in ensuring the full social participation of students with disabilities in inclusive settings, more research should be focused on the attitudes of students towards their peers with disabilities since this can help inform policies that would help curb the negative attitudes that persons with disabilities experienced from their peers.

\section{Conclusion}

The attitudes of students towards their typically developing peers with disabilities at the Ghana National Basic School were neutral. However, there was no statistically significant difference in the attitudes of boys and girls towards their peers with disabilities. Also, no significant difference was found for age and having a friend or relative with disabilities.

\section{Conflict of Interest Statement}

The authors declare no conflicts of interests.

\section{About the Authors}

Francis Kwame Anku is the first author and a teacher at Mfantsipim School in Cape Coast, Ghana. He obtained both his Bachelor of Education in Special Education (Intellectual Disabilities) and English, and a Master of Philosophy in Special Education from the University of Education, Winneba, Ghana. Mr. Anku has practical knowledge in the assessment and remediation of learners with reading difficulties. His research interest is geared towards promoting positive attitudes of non-disabled students towards their peers with special educational needs in inclusive education settings.

Daniel S. Q. Dogbe (Ed.D) obtained his doctoral degree from Ball State University in the United States. He is a former Head of the Department of Special Education at the University of Education, Winneba. He is an expert in braille and a senior lecturer with several years of experience in training professional teachers for the education of individuals with visual impairments. His research interest is focused on demystifying the teaching of mathematics and science to the blind in second- and third-cycle institutions in Ghana.

Anthony Kofi Mensah (PhD), the third author of this article, earned his doctorate degree at the University of Cologne in Germany. Until his recent demise, he was a senior lecturer and Coordinator of Postgraduate Programmes in the Department of Special Education of the University of Education, Winneba. His interest was in learning problems, English as a Foreign Language (EFL) reading, and intervention for struggling readers. 


\section{References}

Agbenyega, J. S. (2007). Examining teachers' concerns and attitudes to inclusive education in Ghana. International Journal of Whole Schooling, 3(1), 41-56.

Alhassan, A. M. (2014). Implementation of inclusive education in Ghanaian primary schools: A look at teachers`attitudes. American Journal of Educational Research, 2(3), 142-148.

Allport, G. W. (1954). The nature of prejudice. Reading, MA: Addison-Wesley.

Aluede, O., Adeleke, F., Omoike, D., \& Afen-Akpaida, J. (2008). A review of the extent, nature, characteristics and effects of bullying behaviour in schools. Journal of Instructional Psychology, 35(2), 151-158.

Amissah, C. M., Gadosey, C. K., Nyarko, K., \& Agyemang, C. B. (2016). Contextual analyses of attitudes toward persons with physical disabilities. Current Research in Psychology, 7(2), 27-35. https://doi.org/10.3844/crpsp.2016.27.35.

Amponteng, M., Opoku, M. P., Agyei-Okyere, E., Afriyie, S. A., \& Tawiah, R. (2019). Understanding of inclusive education practices among parents in Ghana. Journal of Research in Special Educational Needs, 19(3), 207-219.

Annan, I. K. (2014). Assessing barriers faced by pupils with disabilities in inclusive and non-inclusive schools in the Cape Coast Metropolitan area. Thesis submitted to the School of Graduate Studies, Kwame Nkrumah University of Science and Technology. Retrieved from http://ir.knust.edu.gh/bitstream/123456789/9136/1/ISAAC\%20KWESI\%20ANNA N.pdf.

Arthur, A., Odoom, J. A., \& Boateng, A. (2016). Innovative policy 2016 on inclusive education and ICT: Inclusive education rolled out throughout Ghana. Retrieved from https://zeroproject.org/policy/ghana/

Asamoah, E., Ofori-Dua, K., Cudjoe, E., Abdullah, A., \& Nyarko, J. A. (2018). Inclusive education: Perception of visually impaired students, students without disability, and teachers in Ghana. Sage Open, 8(4), 2158244018807791.

Avramidis, E., \& Kalyva, E. (2007). The influence of teaching experience and professional development on Greek teachers' attitudes towards inclusion. European Journal of Special Needs Education, 22(4), 367-389.

Bebetsos, E., Zafeiriadis, S., Derri, V., \& Kyrgiridis, P. (2013). Relationship among students' attitudes, intentions and behaviors towards the inclusion of peers with disabilities, in mainstream physical education classes. International Electronic Journal of Elementary Education, 5(3), 233-248.

Beck, A. R., Fritz, H., Keller, A., \& Dennis, M. (2000). Attitudes of school-aged children toward their peers who use augmentative and alternative communication. AAC: Augmentative and Alternative Communication, 16(1), 13-26.

Boakye-Akomeah, E. (2015). Perception of teachers on inclusive education in selected basic schools in the Cape Coast Metropolis of Ghana. Unpublished Thesis, University of Cape Coast. 
Brook, U., \& Galili, A. (2000). Knowledge and attitudes of high school pupils towards children with special health care needs: An Israeli exploration. Patient Education and Counseling, 40(1), 5-10.

Bunch, G., \& Valeo, A. (2004). Student attitudes toward peers with disabilities in inclusive and special education schools. Disability $\mathcal{E}$ Society, 19(1), 61-76.

Causarano, A. (2019). The social construction of disability in children's books. Pedagogical Approaches. Retrieved from https://www.researchgate.net/publication/331211882 The Social Construction $\mathrm{O}$ f Disability in Children's Books Pedagogical Approaches

Chitiyo, M., Kumedzro, F. K., Hughes, E. M., \& Ahmed, S. (2019). Teachers' Professional Development Needs Regarding Inclusive Education in Ghana. International Journal of Whole Schooling, 15(2), 53-79.

Danso, J. B. (2009). Evaluation of inclusive education practice in Ghana: Survey of inclusive pilot schools. Unpublished Thesis, University of Cape Coast.

Dare, L., Nowicki, E., \& Felimban, H. (2017). Saudi children's thoughts on inclusive education. International Journal of Inclusive Education, 21(5), 532-543.

de Boer, A., \& Pijl, S. J. (2016). The acceptance and rejection of peers with ADHD and ASD in general secondary education. The Journal of Educational Research, 109(3), 325332.

de Boer, A., Pijl, S. J., \& Minnaert, A. (2010). Attitudes of parents towards inclusive education: A review of the literature. European Journal of Special Needs Education, 25(2), 165-181.

de Boer, A., Pijl, S. J., \& Minnaert, A. (2012). Students' attitudes towards peers with disabilities: A review of the literature. International Journal of Disability, Development and Education, 59(4), 379-392.

de Boer, A., Pijl, S. J., \& Minnaert, A. (2014). Evaluating the effectiveness of an intervention program to influence attitudes of students towards peers with disabilities. Journal of Autism and Developmental Disorders, 44(3), 572-583. https://doi.org/10.1007/s10803-013-1908-6.

de Boer, A., Pijl, S. J., \& Minnaert, A. (2012). Students' attitudes towards peers with disabilities: A review of the literature. International Journal of Disability Development and Education, 59(4), 379-392.

de Boer, A., Pijl, S. J., Post, W., \& Minnaert, A. (2012). Which variables relate to the attitudes of teachers, parents and peers towards students with special educational needs in regular education? Educational Studies, 38(4), 433-448.

Diamond, K. E., Hong, S. Y., \& Tu, H. (2008). Context influences preschool children's decisions to include a peer with a physical disability in play. Exceptionality, 16(3), 141-155.

Dias, P. C., Mamas, C., \& Gomes, R. (2020). Attitudes of students towards peers with special educational needs in mainstream Portuguese schools. European Journal of Special Needs Education, 35(5), 636-647. 
Downing, J. E., \& Peckham-Hardin, K. D. (2007). Inclusive education: What makes it a good education for students with moderate to severe disabilities? Research and Practice for Persons with Severe Disabilities, 32(6), 16-30.

Dyson, L. L. (2005). Kindergarten children's understanding of and attitudes toward people with disabilities. Topics in Early Childhood Special Education, 25(2), 95-105.

Estell, D. B., Jones, M. H., Pearl, R., \& Acker, R. V. (2009). Best friendships of students with and without learning disabilities across late elementary school. Exceptional Children, 76(1), 110-124.

Favazza, P. C., Phillipsen, L., \& Kumar, P. (2000). Strategies designed to promote and measure acceptance: A follow-up study of efficacy and reliability. Exceptional Children, 66(4), 491-508.

Feldman, R. (1993). Understanding psychology (3rd ed.). New York: McGraw-Hill.

Flem, A., \& Keller, C. (2000). Inclusion in Norway: A study of ideology in practice. European Journal of Special Needs Education, 15(2), 188-205.

Freer, J. (2018). The educators' attitudes toward disability scale (EADS): A pilot study. International Journal of Disability, Development and Education, 65(6), 581-598.

Gall, M. D., Borg, W. R., \& Gall, J. P. (1996). Research methods. In M. D. Gall, W. R. Borg, \& J. P. Gall (Eds.). Educational research: An introduction (pp. 165-370). New York: Longman.

Garrote, A., \& Rachel S. (2015). Social participation in inclusive classrooms: Empirical and theoretical foundations of an intervention programme. Journal of Cognitive Education and Psychology, 14(3), 375-388. https://doi.org/10.1891/1945-8959.14.3.375

Garrote, A., Felder, F., Krahenmann, H., Schnepel, S., Sermier Dessemontet, R., \& Moser Opitz, E. (2020). Social acceptance in inclusive classrooms: The role of teacher attitudes toward inclusion and classroom management. Frontiers in Education, 15(2), 198-222. Retrieved from https://doi.org/10.3389/feduc.2020.582873.

Gilson, C. B., Gushanas, C. M., Li, Y-F., \& Foster, K. (2020). Defining inclusion: Faculty and student attitudes regarding postsecondary education for students with intellectual and developmental disabilities. Intellectual and Developmental Disabilities, 58(1), 65-81.

Hayes, A. M., \& Bulat, J. (2017). Disabilities inclusive education systems and policies guide for low- and middle-income countries. Research Triangle Park, NC: RTI Press.

Hayford, S. K. (2013). Special educational needs and quality education for all. Accra: Salt and Light.

Hellmich, F., \& Loeper, M. F. (2019). Children's attitudes towards peers with learning disabilities: The role of perceived parental behaviour, contact experiences and selfefficacy beliefs. British Journal of Special Education, 46(2), 157-179.

Hong, S. Y., Kwon, K., \& Jeon, H. J. (2014). Children's attitudes towards peers with disabilities: Associations with personal and parental factors. Infant and Child Development, 23(2), 170-193.

Hong, S-Y., Eum, J., Long, Y., Wu, C., \& Welch, G. (2020). Typically developing preschoolers' behavior toward peers with disabilities in inclusive classroom 
contexts. Journal of Early Intervention, 42(1), 49-68. https://doi.org/10.1177/1053815119873071.

Humphrey, N., \& Symes, W. (2013). Inclusive education for pupils with autistic spectrum disorders in secondary mainstream schools: teacher attitudes, experience and knowledge. International Journal of Inclusive Education, 17(1), 32-46.

Kurtts, S., \& Gavigan, K. (2017). Understanding (dis)abilities through children's literature. Faculty Publications, 31(3), 259.

Kwon, K-A., Hong, S-Y., \& Jeon, H-J. (2017). Classroom readiness for successful inclusion: Teacher factors and preschool children's experience with and attitudes toward peers with disabilities. Journal of Research in Childhood Education, 31(3), 360-378.

Lalvani, P. (2015). Rethinking disability and inclusive education: A teacher study group. Review of Disability Studies: An International Journal, 11(3). Retrieved from http://www.rdsjournal.org/index.php/journal/article/view/515.

Lindsay, S., \& Cancelliere, S. (2018). A model for developing disability confidence. Disability and Rehabilitation, 40(18), 2122-2130. https://doi.org/10.1080/09638288.2017.1326533.

Lund, R., Nielsen, K. K., Hansen, D. H., Kriegbaum, M., Molbo, D., Due, P., et al. (2009). Exposure to bullying at school and depression in adulthood: A study of Danish men born in 1953. European Journal of Public Health, 19(1), 111-116.

MacMillan, M., Tarrant, M., Abraham, C., \& Morris, C. (2014). The association between children's contact with people with disabilities and their attitudes towards disability: A systematic review. Developmental Medicine and Child Neurology, 56(6), 529-546. https://doi.org/10.1111/dmcn.12326.

McDougall, J., Dewit, D. J., King, G., Mille, L. T., \& Steve, K. (2004). High school-aged youths' attitudes toward their peers with disabilities: The role of school and student interpersonal factors. International Journal of Disability, Development $\mathcal{E}$ Education, 51(3), 287-313.

Mieghem, A. V., Verschueren, K., Petry, K., \& Struyf, E. (2020), An analysis of research on inclusive education: A systematic search and meta review. International Journal of Inclusive Education, 24(6), 675-689.

Mjaavatn, P. E., Frostad, P., \& Pijl, S. J. (2015). Measuring the causes for the growth in special needs education: A validation of a questionnaire with possible factors explaining the growing demand for special provisions in education. European Journal of Special Needs Education, 30(4), 565-574.

Nowicki, E. A., \& Sandieson, R. (2002). A meta-analysis of school-age children's attitudes towards persons with physical or intellectual disabilities. International Journal of Disability, Development and Education, 49(3), 243-265. https://doi.org/10.1080/1034912022000007270

Olaleye, A. O., Ogundele, O., Deji, S., Ajayi, O., Olaleye, O., \& Adeyanju, T. (2012). Attitudes of students towards peers with disability in an inclusive school in Nigeria. Disability, CBR and Inclusive Development, 23(3), 65-75. https://doi.org/0.5463/dcid.v23i3.136. 
Peck, C. A., Staub, D., Gallucci, C., \& Schwartz, I. (2004). Parent perception of the impacts of inclusion on their nondisabled child. Research and Practice for Persons with Severe Disabilities, 29(2), 135-143.

Petry, K. (2018). The relationship between class attitudes towards peers with a disability and peer acceptance, friendships and peer interactions of students with a disability in regular secondary schools. European Journal of Special Needs Education, 33(2), 254268.

Pettigrew, T. F. (1998). Intergroup contact theory. Annual Review of Psychology, 49(1), 6585.

Pettigrew, T. F. (2011). When groups meet: The dynamics of intergroup contact (Psychology Press, 2011),

Pettigrew, T. F. (1998). Intergroup contact theory. Annual Review of Psychology, 49(1), 6575.

Pijl, S. J. (2005). Interventions for social integration: Training of social skills for students with disabilities in regular education (in Dutch). In B. F. van der Meulen, C. Vlaskamp, \& K. C. van den Bos (Eds.), Interventions in special needs education (pp. 122-135). Rotterdam, The Netherlands: Lemniscaat B.V

Pijl, S. J., Frostad, P., \& Flem, A. (2008). The social position of pupils with special needs in regular schools. Scandinavian Journal of Educational Research, 52(4), 387-405.

Purutcuoglu, E., \& Dogan, I. (2015). The attitudes of normally developing students towards peers with special educational needs in mainstream classes. proceedings of international academic conferences 2604223. International Institute of Social and Economic Sciences. Retrieved from https://ideas.repec.org/p/sek/iacpro/2604223.html.

Rose, C. A., Stormont, M., Wang, Z., Simpson, C. G., Preast, J. L., Green, A. L., \& Nickerson, A. B. (2015). Bullying and students with disabilities: Examination of disability status and educational placement. School Psychology Review, 44(4), 425444.

Rosenbaum, P. L., Armstrong, R. W., \& King, S. M. (1986). Children's attitudes toward disabled peers: A self-report measure. Journal of Pediatric Psychology, 11(4), 51730 .

Rosenbaum, P. L., Armstrong, R. W., \& King, S. M. (1988). Determinants of children's attitudes towards disability: A review of evidence. Care of Children's Health, 17(1), 32-39.

Rossetti, Z. (2014). Peer interactions and friendship opportunities between elementary students with and without autism or developmental disability. Inclusion, 2(4), 301315.

Schwab, S. (2015). Social dimensions of inclusion in education of 4 th and 7 th grade pupils in inclusive and regular classes: Outcomes from Austria. Research in Developmental Disabilities, 43(44), 72-79.

Schwab, S. (2017). The impact of contact on students' attitudes towards peers with disabilities. Research in Developmental Disabilities, 62(1), 160-165. 
Schwab, S., Huber, C., \& Gebhardt, M. (2016). Social acceptance of students with Down's syndrome and students without disability. Educational Psychology. 36(8), 15011515. https://doi.org/10.1080/01443410.2015.1059924.

Subbey, M. (2020). Awareness of basic school heads in Agona Swedru towards the policy of inclusive education in the Ghana Education Service. International Journal of Inclusive Education, 24(3), 341-350.

Tamakloe, D. (2018). A case study of preschool teachers' pedagogical behaviors and attitudes toward children with disabilities. International Journal of Whole Schooling, 14(2), 83-103.

Tavares, W. (2011). An evaluation of the kids are kids' disability awareness programme: Increasing social inclusion among children with physical disabilities. Journal of Social Work in Disability E Rehabilitation, 10(1), 25-35.

Tirosh, E., Schanin, M., Reiter, S. (1997). Children's attitudes towards peers with disabilities: The Israeli perspective. Developmental Medicine $\mathcal{E}$ Child Neurology, 39(12), 811-814.

Triandis, H. C. (1971). Attitudes measurement and methodology. In H. C. Triandis (Ed.), Attitudes and attitude change (pp. 26-59). New York: John Wiley \& Sons.

Underhill, J. C., Ledford, V., \& Adams, H. (2019). Autism stigma in communication classrooms: Exploring peer attitudes and motivations towards interacting with atypical students. Communication Education, 68(2), 175-192.

Vignes, C., Coley, N., Grandjean, H., Godeau, E., Arnaud, C. (2008). Measuring children's attitudes towards peers with disabilities: A review of instruments. Developmental Medicine $\mathcal{E}$ Child Neurology, 50(3), 182-9.

Vignes, C., Godeau, E., Sentenac, M., Coley, N., Navarro, F., Grandjean, H., \& Arnaud, C. (2009). Determinants of students' attitudes towards peers with disabilities. Developmental Medicine E Child Neurology, 51(6), 473-479.

Wang, L., \& Qi, J. (2020). Effect of student-related factors on their attitudes towards peers with disabilities in physical education: Evidence from elementary schools in China. Asia Pacific Journal of Education, 40(2), 143-153.

Williams, S. Q., \& Inkster, C. D. (2005). The Joan K. Blaska collection of children's literature featuring characters with disabilities or chronic illnesses. Journal of Children's Literature, 31(1), 71-78.

Wood, C., \& Orpinas. P. (2020). Victimization of children with disabilities: Coping strategies and protective factors. Disability $\mathcal{E}$ Society. https://doi.org/10.1080/09687599.2020.1802578.

Yu, S., Ostrosky, M. M., \& Fowler, S. A. (2012). Measuring young children's attitudes toward peers with disabilities: Highlights from the research. Early Childhood Special Education, 20(1), 20-27.

Zachary, R. (2014). Peer interactions and friendship opportunities between elementary students with and without autism or developmental disability. Inclusion, 2(4), 301315. 

be applied to their work. Under the terms of this license, no permission is required from the author(s) or publisher for members of the community to copy, distribute, transmit or adapt the article content, providing a proper, prominent and unambiguous attribution to the authors in a manner that makes clear that the materials are being reused under permission of a Creative Commons License. Views, opinions and conclusions expressed in this research article are views, opinions and conclusions of the author(s). Open Access Publishing Group and European Journal of Special Education Research shall not be responsible or answerable for any loss, damage or liability caused in relation to/arising out of conflict of interests, copyright violations and inappropriate or inaccurate use of any kind content related or integrated on the research work. All the published works are meeting the Open Access Publishing requirements and can be freely accessed, shared, modified, distributed and used in educational, commercial and non-commercial purposes under a Creative Commons Attribution 4.0 International License (CC BY 4.0). 